* Mestrando em Direito Público pela Universidade do Vale do Rio dos Sinos- UNISINOS/ RS. Bolsista CAPES/PROSUP. Especialista em Direito Processual pelo Centro Integrado de Ensino Superior do Amazonas. Graduado em Direito pela UFAM. Advogado em Porto Alegre/RS. Professor. E-mail: rsouzasilva@gmail.com

* Doutora em Direito pela UFPR, com período de pesquisas doutorais na Université Paris I - Panthéon Sorbonne e FLACSO, Buenos Aires. PósDoutorado em Madrid, Espanha (UAM). Professora do Programa de Pós-graduação em Direito da UNISINOS. Professora convidada na Université Paris X. Líder do Grupo de Pesquisa |BioTecJus|. E-mail: taysa_sc@hotmail.com

\section{A biotecnologia e a possibilidade de compatibilização das patentes com a proteção dos conhecimentos tradicionais associados}

\author{
BIOTECHNOLOGY AND THE COMPATIBILITY OF \\ PATENTS WITH THE PROTECTION OF ASSOCIATED \\ TRADITIONAL KNOWLEDGE
}

\author{
Rodolfo Souza da Silva * \\ Taysa Schiocchet **
}

RESUMO: O presente trabalho tece algumas considerações sobre o exercício do direito de patente, quando protege produtos desenvolvidos pela biotecnologia, criados com base em conhecimentos tradicionais associados. Para tanto analisa as possíveis limitações que ele pode causar na prática desses conhecimentos e aos povos detentores, de modo a demonstrar uma possível compatibilização entre a patente e a proteção do saber tradicional a partir da leitura constitucional do TRIPS e da Lei de Propriedade Industrial, feita a partir do princípio da função social da propriedade e dos pilares que regem atividade econômica. A metodologia utilizada foi de natureza qualitativa, de caráter exploratório, mediante um levantamento bibliográfico e documental, a partir de uma perspectiva interdisciplinar.

Palavras-chaves: Biotecnologia. Patentes. Conhecimentos. Tradicionais Associados. Atividade Econômica.

Abstract: The present paper presents some considerations about the exercise of patent rights when it protects the products developed by biotechnology, created with bases on associated traditional knowledge. For such, it analyzes the possible limitations that it can cause in the practice of these knowledge and to the people that own it, seeking a way to demonstrate a possible compatibility between the patent and the protection of traditional knowledge from the constitutional reading of TRIPS and Industrial Property Law, made from the principle of the social function of property and the pillars wich rule economic activity. The methodology utilized was of a qualitative nature, with an exploratory character, through a bibliographic and documental research, from an interdisciplinary perspective.

Keywords: Biotechnology. Patents. Associated Traditional Knowledge. Economic Activity. 


\section{INTRODUÇÃO}

Nos últimos tempos o desenvolvimento do mercado econômico acarretou diversas mudanças na sua dinâmica, principalmente nos dias atuais. Durante este processo a propriedade obteve diversas feições, indo da apropriação de bens ligados à terra, até as formas mais complexas nas quais são apropriáveis, incluindo bens e valores despidos de existência tangível.

A partir da Revolução industrial a evolução tecnológica permitiu a produção de uma série de produtos comercializáveis, o que gerou uma aceleração do processo informacional. Diante desse panorama, mostrou-se necessário a criação de novas modalidades proprietárias, dentre as quais se destaca a propriedade intelectual, caracterizada por ser produto do intelecto do homem, seja através da técnica, originando a propriedade industrial, seja por meio do senso estético, dando vazão à propriedade autoral.

Com o crescimento do mercado biotecnológico, que tem como matériaprima de seus produtos os recursos da biodiversidade, muitas das vezes produzidos com base em conhecimentos tradicionais associados, a obtenção de patentes a partir deles tem se tornado constante.

O instituto da propriedade tem como escopo garantir ao proprietário a faculdade de usar, gozar e dispor da coisa e a de reavê-la de quem quer que a detenha ou possua, calcando-se assim numa regra de exclusão, fundamentada na inviolabilidade dos bens integrantes do patrimônio do indivíduo. Regra esta também utilizada pelas Patentes, que além de garantir a propriedade ao autor da invenção ou modelo de utilidade, excluem terceiros, sem prévia autorização do detentor e a respectiva remuneração, do seu uso, comercialização e venda. Porém, esse regramento é diferente do que gira em torno dos saberes tradicionais, pois são conhecimentos acumulados e construídos ao longo do tempo por um povo, fundados em práticas, tradições, cultura e usos, associados ou não à natureza na qual vivem, passados de geração em geração e podendo ou não serem compartilhados com outros povos.

Surge então um problema no caso das patentes biotecnológicas que envolvem conhecimentos tradicionais associados, pois a atribuição do regime privado da propriedade ao saber coletivo pode gerar efeitos negativos aos povos e comunidades detentores, seja na sua relação com o meio ambiente, 
seja nas suas práticas culturais, em virtude do caráter coletivo em que esses saberes são criados e praticados.

Diante desse panorama, o presente texto pretende analisar as questões que giram em torno da Propriedade Intelectual, no caso das Patentes, evidenciando os efeitos do exercício desse direito e as potenciais limitações que ele pode causar aos detentores dos saberes tradicionais, na sua relação com o meio ambiente e nas suas práticas culturais. Com isso, busca-se demonstrar a possibilidade de compatibilização da proteção dada às patentes biotecnológicas e a proteção dos conhecimentos tradicionais a partir da leitura constitucional do Acordo TRIPS e da Lei de Propriedade Industrial, feita com base no princípio da função social da propriedade, o qual legitima o exercício da propriedade, impondo-lhe um dever/função, bem como com o a preservação do meio ambiente, princípio basilar da atividade econômica, de modo a estabelecer um diálogo entre tais marcos normativos com os limites postos pela Constituição Federal.

Por fim, a metodologia utilizada nesta pesquisa foi de natureza qualitativa, de caráter exploratório, mediante um levantamento bibliográfico e documental.

\section{O EXERCÍCIO DOS DIREITOS DE PROPRIEDADE INTELECTUAL E SEUS EFEITOS}

O ânimo de propriedade esteve presente nas sociedades desde os tempos mais remotos, ganhando espaço ao longo do processo civilizatório, na medida em que surgiam organizações sociais mais complexas. Ao decorrer da história e do desenvolvimento econômico e social, a propriedade assumiu os mais diversos aspectos, desde os mais primitivos, nos quais abarcava somente os bens materiais, até os mais complexos, passando a incorporar tantos os bens materiais, quanto aqueles despidos de existência material (AZEVEDO, 2008, p.98).

O fundamento da propriedade privada é a exclusão, calcada na inviolabilidade da pessoa e dos bens que integram o seu patrimônio ${ }^{1}$. Atualmente, com a valorização do conhecimento e da informação, a partir

\footnotetext{
${ }^{1} \mathrm{O}$ Código Civil Brasileiro no seu art.1.228 relaciona o direito de propriedade às faculdades de usar, gozar, dispor da coisa e o direito de reavê-la do poder de quem injustamente a possua ou detenha. Assim também entendem os civilistas brasileiros acerca do direito de propriedade.
} 
da dinâmica industrial de produção, concorrência e exclusividade de bens e serviços, a propriedade material deixou de ser o único foco de valorização de bens, passando a albergar também a produto do intelecto humano.

Essa novel espécie de propriedade é chamada de Propriedade Intelectual e segundo Del Nero (2004, p.69-70) é gênero, dos quais são espécies: proteção dos direitos autorais, dos programas de computador, dos direitos de propriedade industrial e das obtenções vegetais ou de cultivares.

Ao longo dos anos, visando unificar a proteção dada a Propriedade Intelectual, foram elaborados diversos tratados internacionais (DEL NERO, 2004), os quais fixaram os princípios básicos a serem seguidos e praticados pelos países que os reconhecem. O mais atual tratado relativo aos Direitos de Propriedade Intelectual é o Acordo TRIPS (Trade Related Aspects of Intelectual Property) firmado em 1995.

Após insistência dos Estados Unidos e de outros países desenvolvidos, o tema da propriedade intelectual foi inserido nas discussões da Rodada Multilaterais de comércio, convocada pelo GATT $^{2}$, sendo criado no seu âmbito um grupo de trabalho sobre o TRIPS, após difíceis negociações com os participantes (DEL NERO, 2004, p.58).

Segundo relata Del Nero (2004, p.59) a Ata Final da Rodada Uruguai de Negociações Multilaterais do GATT tratou da propriedade intelectual, abrangendo as seguintes modalidades de proteção: direitos do autor, marcas, indicações geográficas, desenhos industriais, topografia de circuitos integrados e patentes. A mencionada Ata foi redigida em 15 de abril de 1994 e referendada pelo Congresso Nacional, tornando-se o Brasil signatário desse tratado internacional ${ }^{3}$.

O TRIPS representa uma tentativa de regular e proteger diferentes bens imateriais do mundo. É um acordo complexo, não apenas pelo seu conteúdo substantivo e adjetivo, mas pelo enfoque dado ao tema, vinculando à vida econômica e comercial. No âmbito nacional e em consonância com o mencionado acordo, temos a Lei de Propriedade Industrial que garante a propriedade ao autor da invenção ou modelo de utilidade e confere ao seu

\footnotetext{
${ }^{2}$ General Agreement on Tariffs and Trade (GATT), instituição criada em 1947 e base da Organização Mundial do Comércio. Grupo de normas e concessões tarifárias criadas para impulsionar a liberalização comercial e combater as práticas protecionistas entre as nações.

${ }^{3}$ Ata ratificada pelo Brasil através do Decreto Legislativo n.30 de 15 de dezembro de 1994 do Congresso Nacional e promulgada através do Decreto n. 1.355 de 30 de dezembro de 1994 da Presidência da República.
} 
titular o direito de impedir terceiro, sem o seu consentimento, de produzir, usar, colocar à venda, vender ou importar ${ }^{4}$.

Todo esse regramento inerente ao exercício do direito de propriedade permite que a Propriedade intelectual seja uma ferramenta de estímulo para o desenvolvimento socioeconômico, pois há retorno do investimento feito pelo criador ou inventor na criação dos inventos e na produção e prestação de bens e serviços.

Nesse sentido entendem Thaines e Meleu (2011, p.64) ao afirmarem que,

[...] a proteção da propriedade intelectual garante ao titular da tecnologia o retorno dos investimentos gastos em pesquisa e desenvolvimento (P\&D). Além disso, assegura maior competitividade às empresas e organizações, especialmente na produção e geração de serviços, uma vez que auxilia os consumidores na satisfação de suas necessidades, bem como coíbe a concorrência desleal por meio da defesa da procedência e da qualidade dos produtos e serviços, tornando a proteção da propriedade imaterial e do capital intelectual importantes ativos para as empresas ${ }^{5}$.

No seara da Biotecnologia as empresas utilizam como matéria prima recursos da biodiversidade, de onde se retiram o material genético para pesquisas e desenvolvimento de produtos. Para obter tais recursos demanda-se bastante tempo e um alto investimento em tecnologias para pesquisas. Ao longo do desenvolvimento dessas atividades constatou-se que uma maneira rápida e econômica de acessar ${ }^{6}$ os recursos biológicos e genéticos da biodiversidade foi

\footnotetext{
${ }^{4}$ A Lei n.9.279/96 que regula direitos e obrigações relativos à Propriedade Industrial assim dispõe: Art.42. A patente confere ao seu titular o direito de impedir terceiro, sem o seu consentimento, de produzir, usar, colocar à venda, vender ou importar com estes propósitos:

I - produto objeto de patente;

II - processo ou produto obtido diretamente por processo patenteado.

$\S 1^{\circ}$ Ao titular da patente é assegurado ainda o direito de impedir que terceiros contribuam para que outros pratiquem os atos referidos neste artigo.

$\S 2^{\circ}$ Ocorrerá violação de direito da patente de processo, a que se refere o inciso II, quando o possuidor ou proprietário não comprovar, mediante determinação judicial específica, que o seu produto foi obtido por processo de fabricação diverso daquele protegido pela patente.

${ }^{5}$ Nessa mesma linha entende Lange Canhos (1991, p.2) ao sustentar que além de procurar proteger e recompensar o autor, a patente tem como meta estimular o progresso industrial através da divulgação do invento. O sistema é muito claro: o autor torna público seu invento público e em troca, durante um período limitado de tempo, ele tem o direito de impedir a exploração desse invento por terceiros. Desta forma, o seu trabalho e capacidade são recompensados e, ao mesmo tempo, o avanço tecnológico é incentivado mediante a disseminação publica de informações sobre o invento.

${ }^{6}$ É a atividade realizada sobre o patrimônio genético com o objetivo de isolar, identificar ou utilizar informação de origem genética ou moléculas e substâncias provenientes do metabolismo dos seres vivos e de extratos obtidos destes organismos, para fins de pesquisa científica, desenvolvimento tecnológico ou bioprospecção, visando a sua aplicação industrial ou de outra natureza. (BRASIL, 2013).
} 
através das comunidades e povos locais, detentores de conhecimentos tradicionais associados, tornando-os por consequência objeto de patentes.

Pertinente, nesse contexto, as considerações de Vandana Shiva (2001, p.101) ao afirmar que dos 120 princípios ativos atualmente isolados de plantas superiores, e largamente utilizados na medicina moderna, $75 \%$ tem utilidades que foram identificadas pelos sistemas tradicionais. Menos de doze são sintetizados por modificações químicas simples; o resto é extraído diretamente de plantas e depois purificado. Diz-se que o uso do conhecimento tradicional aumenta a eficiência de reconhecer as propriedade medicinais de plantas em mais de $400 \%$

Considerando que os direitos de patentes também tem como base para o seu exercício o regramento da exclusão e são bastante utilizados para a proteção de bioprodutos desenvolvidos e criados com base em conhecimentos tradicionais associados, há possibilidade de que essa proteção gere efeitos negativos às comunidades e povos detentores, no que pertine às limitações nas práticas desse saber e no risco de sua própria preservação, em virtude da criação, prática e transmissão desse conhecimento possuir um aspecto coletivo e não de exclusão de terceiros.

\section{OS CONHECIMENTOS TRADICIONAIS ASSOCIADOS E AS POSSÍVEIS LIMITAÇÕES OCASIONADAS PELAS PATENTES BIOTECNOLÓGICAS AOS POVOS E COMUNIDADES LOCAIS}

Conhecimentos Tradicionais Associados, na definição de Marques (2007, p.352),

é o conjunto de saberes - de saber-fazer (know how) - que certas populações e indivíduos detêm a respeito do mundo natural e sobrenatural, atinentes à utilização de materiais biológicos vegetais, animais e microbianas, transmitido oralmente de geração em geração, por isso mesmo inseridos nas tradições culturais e espirituais dessas populações. Cura-se, portanto, de um acervo de "informações" não sistemáticas, vazadas não raro em práticas culturais, individuais ou coletivas, partilhadas (e, as mais das vezes, transmitidas intergeracionalmente) por certas comunidade humanas (ou por indivíduos que as integram, em territórios mais ou menos determinados, com valor actual ou potencial, associado às informações genéticas preexistentes em espécies 
animais, vegetais, microbianas ou em substâncias provenientes do metabolismo desses seres vivos; conhecimentos que são atinentes à localização, identificação, caracterização e utilização das propriedades ou características dessas substâncias [...].

Tais saberes são inerentes à vida dos povos e comunidades tradicionais, pois intimamente ligados ao cotidiano, notadamente nas suas práticas culturais, consubstanciadas na própria identidade dessas populações. Elas atribuem diversas significações a estes saberes. Identifica Derani (2002, p.153) cinco elementos característicos de uma comunidade tradicional:

1. propriedade comunal; 2. produção voltada para dentro (valor de uso); 3 . Distribuição comunitária do trabalho não assalariado; 4. tecnologia desenvolvida e transmitida por processo comunitário, a partir da disposição de adaptação ao meio em que se estabelecem; 5. Transmissão da propriedade, conhecimento, pela tradição comunitária, intergeracional.

Como exemplo desses conhecimentos, temos uma tradição dos indígenas amazônicos Wajãpis, que consiste em utilizar tintas vegetais para adornar seus corpos e outros objetos com motivos geométricos. Através de linguagem única, que mistura artes gráficas e verbais e reflete a própria visão de mundo, eles transmitem os conhecimentos essenciais para a vida em comunidade. Essa arte é chamada de kusiwa e é feita de uma tinta vegetal vermelha extraída de uma planta regional amazônica, o urucum. Esta arte corporal possui significados sociológicos, culturais, estéticos, religiosos e metafísicos e partir dela a comunidade é estruturada. ${ }^{7}$

Sem adentrar na discussão de quem é o proprietário do saber, pois vários povos de uma mesma região podem praticar o conhecimento tradicional, fato é que esses conhecimentos possuem um aspecto comunitário, coletivo, sendo possível até afirmar que se trata de uma propriedade coletiva, pois, como visto, é construído sobre um significado, praticado e compartilhado em comunidade. Acontece que esses conhecimentos tradicionais são manifestações com potencial valor econômico para a indústria biotecnológica, sendo, como já discorrido, matéria prima deste novel mercado. Por isso, muitas das empresas costumam se apropriar e patentear esses conhecimentos tradicionais.

\footnotetext{
${ }^{7}$ Comunidade de índios tupis que vivem na região delimitada do rio Oiapoque, Jari e Araguari no Amapá. Possuem 580 membros e estão divididos em 40 aldeias agrupadas. Para mais detalhes e informações (UNESCO, 2008).
} 
Contudo, o direito garantido às empresas de proteger o seu invento e criação através das patentes pode causar restrições aos povos e comunidades tradicionais detentores desses saberes. Caso de bastante repercussão foi o da obtenção indevida dos saberes tradicionais das Ervateiras do Mercado Ver-opeso em Belém/PA, o que lhe causou restrições às suas práticas culturais. (GLASS, 2006).

\section{Vandana Shiva (2001, p.32) enumera duas restrições:}

[...] a primeira restrição é a mudança de direitos coletivos para direitos privados. Conforme declara o preâmbulo do acordo, os Direitos de Propriedade Intelectual são reconhecidos apenas como direitos privados. Isso exclui todos os tipos de conhecimento, idéias e inovações que acontecem nas "terras comunitárias intelectuais" - nos povoados entre os lavradores, nas florestas entre os povos tribais, e até mesmo nas universidade entre os cientistas. $\mathrm{O}$ acordo sobre os TRIPS é, portanto, um mecanismo para a privatização das "terras comunitárias intelectuais" e a desintelectualização da sociedade civil. A mente se torna um monopólio das grandes empresas. A segunda restrição dos Direitos de Propriedade Intelectual é que eles são reconhecidos apenas quando o conhecimento e a inovação deve ter potencialmente uma aplicação industrial. Isto imediatamente exclui todos os setores que produzem e inovam fora do modo de organização industrial. $\mathrm{O}$ lucro e a acumulação de capital são os únicos fins da criatividade; o bem social não é mais reconhecido. Sob o controle das corporações, ocorre a "desindustrialização" das produções em pequena escala nos setores informais da sociedade.

Prevendo a situação de obtenção do saber e do seu patenteamento foi que o Governo Federal elaborou a Medida Provisória $n^{\circ} 2.186-16 / 01^{8}$, a qual determina a repartição de benefícios, o consentimento prévio informado e menção ao detentor do conhecimento. Medidas estas também previstas na Convenção de Diversidade Biológica ${ }^{9}$, assinada na ECO-92 no Rio de Janeiro, na Conferência das Nações Unidade para o Meio Ambiente e Desenvolvimento (CNUMAD).

\footnotetext{
${ }^{8}$ Regulamenta o inciso II do $\S 1$ e e o $\S 4$ o do art. 225 da Constituição, os arts. 1ํㅗ 8oㅡ, alínea “j”, 10, alínea "c", 15 e 16, alíneas 3 e 4 da Convenção sobre Diversidade Biológica, dispõe sobre o acesso ao patrimônio genético, a proteção e o acesso ao conhecimento tradicional associado, a repartição de benefícios e o acesso à tecnologia e transferência de tecnologia para sua conservação e utilização, e dá outras providências.

${ }^{9}$ Essa Convenção abarca tudo o que se refere direta ou indiretamente à biodiversidade - e ela funciona, assim, como uma espécie de arcabouço legal e político para diversas outras convenções e acordos ambientais mais específicos, como o Protocolo de Cartagena sobre Biossegurança; o Tratado Internacional sobre Recursos Fitogenéticos para a Alimentação e a Agricultura; as Diretrizes de Bonn;
} 
Mesmo com a previsão do direito à repartição de benefícios e do consentimento prévio informado das comunidades e povos detentores, ainda assim as restrições que podem sofrer estes grupos continuam a existir em virtude da imposição de significados acerca do conhecimento, econômico e privado dado pela indústria, sobre os mais variados significados de caráter coletivo, dado pelas comunidades e povos.

Assim também entende Flores Filho (2011, p.163) em suas considerações:

A imposição de propriedade compartilhada sobre conhecimentos que antes eram de domínio público - ou, em palavras mais simples, eram livremente repassados entre as pessoas - transporta a lógica do comércio para um espaço que antes era dominado por valores mais próximos da solidariedade. Além disso, as relações sociais de compartilhamento desses conhecimentos, o âmbito dos conceitos de "comunidade" para os envolvidos e a amplitude da proteção necessária podem não serem compatíveis com o conceito de propriedade privada moderna, como bem relatou Carpenter (2004) num artigo sobre a propriedade cultural dos indígenas. Se essa incompatibilidade ocorrer, não será a simples estipulação de direito que permitirá um "benefício" para comunidade.

Nos dias de hoje verifica-se claramente essa transposição comercial aos detentores de conhecimentos tradicionais, quando algumas indústrias ${ }^{10}$ repartem

as Diretrizes para o Turismo Sustentável e a Biodiversidade; os Princípios de Addis Abeba para a Utilização Sustentável da Biodiversidade; as Diretrizes para a Prevenção, Controle e Erradicação das Espécies Exóticas Invasoras; e os Princípios e Diretrizes da Abordagem Ecossistêmica para a Gestão da Biodiversidade. A Convenção também deu início à negociação de um Regime Internacional sobre Acesso aos Recursos Genéticos e Repartição dos Benefícios resultantes desse acesso; estabeleceu programas de trabalho temáticos; e levou a diversas iniciativas transversais. Maiores informações (BRASIL, 1992).

${ }^{10}$ A empresa Natura vem construindo um modelo de produção a partir da biodiversidade agregando valor dos conhecimentos tradicionais associados à produção, tecnologia e conceitos inovadores e, a partir disso, transformando esses conhecimentos em matéria-prima e produtos. Esse valor de produção é gerado para as comunidades através da repartição de benefícios, com a distribuição de renda a partir do acesso ao patrimônio genético, revertidas à projetos e atividades escolhidas por elas. Nesse sentido a empresa entende que houve uma evolução de certas comunidades, que começaram a fazer dentro do seu ambiente a produção de óleos, extratos, sendo uma pré-produção, levando as comunidades a se capacitarem e especializarem, sem agredir a natureza e ajudando tais grupos a se tornarem empreendedores. Algumas comunidades já existiam no modelo de cooperativismo, outras ainda estavam num modelo que precisavam se fortalecer como instituição. A empresa é um vetor pra gerar a discussão e esse valor dentro da comunidade, levado através de antropólogos, sociólogos, biólogos e químicos, de modo que possam se desenvolver de maneira sustentável e se tornarem independentes, sem depender do consumo dos próprios produtos da Natura. A empresa trabalha com 25 comunidades Brasil afora, estando o principal núcleo de desenvolvimento na região amazônica. Esse modelo é bastante complexo, pois envolve comunidades, demanda dos consumidores e desenvolvimento de produtos. Exposição no Youtube por Luciana Villa Nova (2011). 
os benefícios obtidos, deixam a cargo das comunidades a destinação e uso desses recursos, fazem com que algumas mudem seu modelo de convívio social e até as incluem na escala inicial de produção de seus bioprodutos.

A repartição de os benefícios oriundos das patentes biotecnológicas significa somente dividir os recursos econômicos obtidos com os bioprodutos. Ao assim proceder está a indústria biotecnológica de acordo com a regulamentações e princípios que envolvem obtenção de patrimônio genético e conhecimentos tradicionais, entretanto, isso não é o suficiente. Ao discorrer sobre a MP n.2.186-16/01, notadamente acerca da repartição de benefícios ali prevista, entende Flores Filho (2011, p.163) que aparentemente, o problema dessa norma não é uma contradição em face dos ideais de justiça distributiva. O problema é que ela não se apresenta como uma verdadeira opção inovadora para a questão dos conhecimentos tradicionais. E, mais, esta opção deixa de lado o fato de que o compartilhamento de benefícios também pode gerar efeitos negativos para a sociedade como um todo e para a própria cultura local.

Considerando que os conhecimentos tradicionais possuem toda uma significação e importância para os povos e comunidades detentores e que os direitos de propriedade intelectual que envolvem tais saberes causam e podem causar restrições na sua prática, há a necessidade de compatibilização desses direitos. Estas restrições vão desde a limitação da prática do saber, na medida em que pode ser afetada a preservação das identidades culturais da comunidade, levando-a a extinção, até o impacto no meio ambiente ${ }^{11}$ onde vivem, pois o saber que proporcionava o manejo ambiental necessário para o equilíbrio do ecossistema deixa de ser praticado pelos grupos tradicionais.

Acerca da relação do conhecimento tradicional associado com o meio ambiente entende Santilli (2005, p.192) que esses saberes vão desde técnicas de manejo de recursos naturais, até métodos de caça e pesca, conhecimentos sobre os diversos ecossistemas e propriedades farmacêuticas, alimentícias e agrícolas de espécies e as próprias categorizações e classificações de espécies de flora e fauna utilizadas.

\footnotetext{
${ }^{11} \mathrm{O}$ impacto é possível pois as comunidades e povos tradicionais ao mesmo tempo em que retiram da natureza aqueles recursos necessários para sua subsistência, preservam os ecossistemas e respeitam os seus ritmos de renovação e equilíbrio, pois essas técnicas e práticas consubstanciam elementos simbólicos e religiosos a partir do meio em que vivem, levando-os a adquirir, ao longo do tempo, profundos conhecimentos acerca das características ambientais e das possibilidades de manejo ambiental dos recursos naturais do território que ocupam, sendo, por isso, importantes para o meio ambiente e para o desenvolvimento sustentável. Essa importância é reconhecida no princípio 22 da Declaração do Rio de Janeiro sobre Meio Ambiente e Desenvolvimento.
} 
Por sua vez Kretzmann e Sparemberguer (2008, p. 109) entendem que a valorização e respeito desses povos detentores de saberes tradicionais e que dependem diretamente da natureza para viver, pode partir também do reconhecimento às formas de manejo que desenvolvem. Essas formas respeitam o ritmo da natureza, como o fato de exercerem a pesca na época adequada e, quando há cheias e piracema, buscarem outra forma de subsistência, como a pequena agricultura e o extrativismo vegetal.

Por isso, considerando a estreita relação da diversidade biológica e cultural, as normas garantidoras do direito de patente não devem ser interpretadas e aplicadas de modo isolado. Ao contrário, devem dialogar com os preceitos que garantam a preservação desses saberes ${ }^{12} \mathrm{e}$, principalmente com a Constituição, para que sob à luz constitucional possam ser exercidos, obedecendo os limites ali estabelecidos e assim possam estar compatíveis com a proteção dos conhecimentos tradicionais.

\section{A COMPATIBILIZAÇÃO DO EXERCÍCIO DOS DIREITOS DE PROPRIEDADE INTELECTUAL E A PROTEÇÃO DOS CONHECIMENTOS TRADICIONAIS ASSOCIADOS}

Com a constante fabricação e patenteamento de produtos biotecnológicos de origem biológica e com base em conhecimentos tradicionais associados, o patrimônio genético e os saberes tradicionais adentraram ao campo jurídico e dele clamaram por normas adequadas e respostas às situações oriundas da novel dinâmica social e industrial, posto que afetam a finalidade e a (in)disponibilidade desses conhecimentos, em vista de suas interações com a administração da vida e de sua preservação.

O que ocorre nos dias de hoje é a aplicação das disposições da Convenção de Diversidade Biológica e da Medida Provisória n. 2.186-16 (consentimento prévio, repartição de benefícios e indicação dos detentores do saber tradicional), em decorrência do exercício do direito de patente previsto na Lei de Propriedade Industrial e no Acordo TRIPS, sendo que este direito de propriedade intelectual é aplicado ou interpretado de forma isolada, sem considerar o sistema jurídico e

\footnotetext{
${ }^{12}$ Pertinente destacar que a Convenção de Diversidade Biológica prevê no seu art.16.5 que os países membros ao reconhecer a existência de patentes e de outros direitos de propriedade intelectual capazes de influenciar na implementação da Convenção, devem cooperar, em conformidade com a legislação nacional e o direito internacional, para garantir que esses direitos de propriedade intelectual apoiem e não se oponham aos objetivos da Convenção.
} 
as situações reflexas que gravitam em torno do fato, notadamente a proteção dos conhecimentos tradicionais, o que leva a ocorrência de restrições ou limitações às práticas desses saberes e a própria preservação dos povos detentores.

Diante desse panorama, compatibilizar toda a sistemática do direito de patente com a proteção do saber tradicional tem sido uma tarefa complicada, podendo-se afirmar na existência de um conflito e uma verdadeira incoerência no sistema jurídico ${ }^{13}$, pois aplica o direito mas não realiza o direito. Na atualidade, manter a coerência do Direito não é uma tarefa simples e fácil. Nesse sentido afirma Lima Marques (2012, p.19):

Reconstruir a coerência do sistema de direito ou de uma ordem jurídica nacional, em tempos pós-modernos, de fragmentação, internacionalização e flexibilização de valores e hierarquias, em tempos de necessária convivência de paradigmas e métodos, de extrema complexidade e pluralismo de fontes, não é tarefa fácil e exige muita ciência e sensibilidade dos juristas.

Ao discorrer sobre o pluralismo pós-moderno e o "diálogo" das fontes Erik Jayme (2003, p.109) afirma que o sistema jurídico pressupõe uma certa coerência - o direito deve evitar a contradição. O juiz, na presença de duas fontes, com valores contrastantes, deve buscar coordenar as fontes, num diálogo das fontes ${ }^{14}$ (Dialog der Quellen).

Focando na necessidade de incorporação de uma pluralidade de fontes e modificando a sua denominação para o "diálogo entre as fontes do Direito", Engelmann (2010, p.297) “[...] propõe um efetivo diálogo, que não exige necessariamente apenas a interlocução de duas (di) fontes, mas uma efetiva reordenação das diversas fontes de onde emergem normas jurídicas".

Nessa proposta de diálogo feita pelo mencionado autor o tradicional modelo piramidal de Kelsen seria substituído pela horizontalização das fontes do Direito, com um fluxo que tem a Constituição como passagem obrigatória,

\footnotetext{
${ }^{13}$ Da leitura das Leis e Convenções Internacionais sobre Propriedade Intelectual percebe-se que conflitam com as disposições da Convenção de Diversidade Biológica e com as normativas que regulam o acesso ao patrimônio genético e o conhecimento tradicional associado pois não preevem o consentimento prévio e informado das comunidades.

${ }^{14}$ Ao trazer para o Brasil a teoria do diálogo das fontes Lima Marques (2012, p.20) afirma que ela significa a aplicação simultânea, coerente e coordenada das plúrimas fontes legislativas, leis e leis gerais, de origem internacional e nacional, as quais tem campos de aplicação convergentes, mas não são mais totalmente coincidentes ou iguais.
} 
sendo responsável pelo filtro de constitucionalidade e pelo lugar central na condução do diálogo entre todas as fontes do Direito.

Analisando as disposições constitucionais que tutelam a diversidade biológica Fiorillo (2012, p.35) entende que o art. 170 da $\mathrm{CF} / 88^{15}$, o qual garante o desenvolvimento econômico atrelado à existência digna, estabelece as regras que devem determinar o regramento do Estado e dos particulares diante da economia, de modo que todo o esforço da ordem econômica seja voltado à proteção do meio ambiente. Trata do desenvolvimento da ordem econômica, com base no capital e no trabalho, assegurando a existência digna, de acordo com os princípios fundamentais apontados em seus incisos.

Em sua fase filosófica, a propriedade é ampla, irrestrita e incondicional, contudo o seu real exercício está condicionado à prévia regulamentação estatal, de modo a sofrer limitações através das manifestações do Estado, visando condicionar as diversas situações relativas não só ao seu exercício, mas também a sua destinação e utilização. Assim é que a própria Constituição Federal ${ }^{16}$ que, em seu art.5 $5^{\circ}$, inciso XXII, assegura o direito de propriedade, estabeleceu no inciso XXIII, do supracitado artigo, o condicionamento desse direito à sua função social (AZEVEDO, 2008, p.99).

Em virtude dessa nova ordem social colocada pela Constituição, pautada na Justiça social, na dignidade e no bem-estar do homem, os institutos do Direito Civil passaram a ser direcionados para a persecução dos fins sociais. No caso da propriedade, o direcionamento foi

\footnotetext{
${ }^{15}$ Art.170. A ordem econômica, fundada na valorização do trabalho humano e na livre iniciativa, tem por fim assegurar a todos a existência digna, conforme os ditames da justiça social, observados os seguintes princípios:

I - soberania nacional;

II - propriedade privada;

III - função social da propriedade;

IV - livre concorrência;

$\mathrm{V}$ - defesa do consumidor;

VI - defesa do meio ambiente, inclusive mediante tratamento diferenciado conforme o impacto ambiental dos produtos e serviços e de seus processos de elaboração e prestação;

VII - redução das desigualdades regionais e sociais;

VIII - busca do pleno emprego;

IX - tratamento favorecido para as empresas de pequeno porte constituídas sob as leis brasileiras e que tenham sua sede e administração no País.

${ }^{16}$ Art. $5^{\circ}$. Todos são iguais perante a lei, sem distinção de qualquer natureza, garantindo-se aos brasileiros e aos estrangeiros residentes no País a inviolabilidade do direito à vida, à liberdade, à igualdade, à segurança e à propriedade, nos termos seguintes:

XXII - é garantido o direito de propriedade;

XXIII - a propriedade atenderá a sua função social.
} 
operacionalizado através da sua função social. Nesse sentido afirma Barbosa (2003) que a propriedade passou a ter um direito-função, ou seja, para ser legítima, esta deve exercer sua função social, uma vez que ela confia ao seu titular o direito/dever de realizar ações importantes para o desenvolvimento socioeconômico do país.

Considerando que as patentes biotecnológicas baseadas em conhecimentos tradicionais associados devem atender o princípio constitucional da função social da propriedade, o qual além de legitimar a propriedade, também deve ser observado no desenvolvimento das atividades econômicas, as disposições do acordo internacional TRIPS, firmado no âmbito das rodadas de comércio que criaram a Organização Mundial do Comércio (OMC), e da Lei de Propriedade Industrial brasileira devem observar os preceitos constitucionais relativos à propriedade, bem como os pilares que regem a atividade econômica.

Dessa maneira a patente estará de acordo com o regramento de proteção dos conhecimentos tradicionais associados, preservando assim a diversidade cultural dos povos e comunidades locais e a diversidade biológica da qual dependem para viver e praticar os saberes tradicionais. Pertinente nesse contexto a afirmação Fiorillo (2012, p.36) ao dizer que para a preservação da existência digna, devemos seguir a principiologia estabelecida no art. 170 da Constituição, evitando assim o crescimento de uma mentalidade voltada à manutenção de um mercado de consumo, sem relevar a importância da preservação da biodiversidade.

$\mathrm{O}$ atendimento à função social da propriedade seria, por exemplo, quando o exercício do direito de patente não cause: a) limitações às práticas do saberes, podendo ele se dar, ainda, no âmbito de uma coletividade, preservando assim as identidades, costumes e significados transmitidos intergeracionalmente; b) a imposição de valores e significações diferentes (principalmente no aspecto econômico e industrial) dos que a comunidade tem perante aquele saber, transformando o seu peculiar modo de viver; c) a obtenção em massa de recursos naturais necessários para o desenvolvimento dos produtos patenteados, de modo a causar danos ao meio ambiente e a prática do saber tradicional pelas comunidades.

Em vista disso, fica evidente que o acordo TRIPS e a Lei de Propriedade Industrial tem como limite o regime jurídico colocado pela $\mathrm{CF}$ / 
88. A atividade da indústria biotecnológica, no caso de patentes com base em conhecimentos tradicionais associados, deve observar os princípios que regem a atividade econômica (art.170) e as disposições sobre os direitos de propriedade intelectual, os quais devem atender sua função social e permitir o desenvolvimento socioeconômico (art. $5^{\circ}$, XXII e XXIII). No caso de não observância desses parâmetros, o direito de patente não estará compatível com a proteção dos saberes tradicionais, bem como com o desenvolvimento cultural e socioeconômico.

\section{CONSIDERAÇÕES FINAIS}

A propriedade, que ao longo do desenvolvimento econômico e social mundial assumiu diversas feições, tornou-se um elemento essencial na estrutura econômica da sociedade, pois baseada na exclusão, permite que o patrimônio do proprietário não seja violado por terceiros, podendo somente aquele utilizar as faculdades de uso, gozo e disposição da coisa.

Com a fabricação de produtos em larga escala e a constante prestação de variados serviços, surgiu a necessidade não somente de tutelar a propriedade sobre o produto, mas a própria ideia que surgiu para a criação daquele produto ou para a prestação daquele serviço. Nesse contexto, o intelecto humano passa a ter a necessidade de ser protegido, surgindo então os Direitos de Propriedade Intelectual, os quais tornaram-se fundamentais no fomento da concorrência no mercado e na atribuição de exclusividade dos produtos e serviços das empresas.

$\mathrm{Na}$ indústria biotecnológica as matérias-primas utilizadas na fabricação de bioprodutos advém dos recursos da biodiversidade. Durante o desenvolvimento das atividades de pesquisa e fabricação verificou-se que a obtenção desses recursos através do conhecimento tradicional associado gera rapidez e economia na elaboração e fabricação de seus bioprodutos. Diante desse panorama de obtenção de recursos biológicos, a comunidade internacional elaborou a Convenção de Diversidade Biológica, prevendo a repartição dos benefícios, o consentimento prévio e informado e a menção das comunidades ou países detentores da biodiversidade e do conhecimento tradicional associado. Baseados nos princípios da CDB o Brasil editou a 
MP 2.186-16/01 e que hoje é o parâmetro legal para a bioprospecção de recursos da biodiversidade.

De outra banda, visando unificar todo o regramento da obtenção de Propriedade Intelectual pelo mundo, os países desenvolvidos propuseram e conseguiram firmar nas rodadas multilaterais antecedentes à criação da Organização Mundial do Comércio o acordo TRIPS, o qual passou a estabelecer um padrão de proteção dos direitos de propriedade intelectual, sem contudo, prever a proteção do conhecimento tradicional associado. Como signatário do acordo, o Brasil elaborou a Lei de Propriedade Industrial a qual, no mesmo sentido, também não estabeleceu mecanismos de proteção aos saberes.

Considerando que o Conhecimento tradicional associado consubstancia elementos simbólicos, religiosos, identitários e com significados inerentes à própria vivência da comunidade, as patentes de bioprodutos com base nesses saberes podem causar restrições ao grupos detentores desses conhecimentos, pois transporta o regime privado da propriedade, fundamentado na exclusão de terceiros e na auferição de retorno econômico, para um contexto de criação coletiva ou, se assim se pode chamar, de uma propriedade coletiva, onde a prática do conhecimento tem caráter significativo para a vida nas mais variadas formas. Em outras palavras, há uma verdadeira imposição de significados que podem repercutir de forma negativa na prática do saber e na preservação do povo ou da comunidade.

A aplicação do princípio da repartição de benefícios previsto na CDB e na Medida Provisória 2.186-16/01 é feita em virtude do exercício do direito de patente previsto no TRIPS e na lei de propriedade industrial. E é nesse contexto que o exercício desse direito deve ser compatibilizado com a proteção do conhecimento tradicional associado, não devendo ser aplicado e interpretado de uma maneira isolada, mas de modo que considerem o sistema jurídico como um todo.

Diante dessa situação de complexidade que envolve questões econômicas e possíveis repercussões que afetem a vida, a finalidade e a (in)disponibilidade desses saberes é que o diálogo entre o diplomas normativos que tratam do direito de patente e a Constituição Federal, que assume um papel condutor nesse diálogo, podem permitir a compatibilização entre o exercício dessa espécie de direito de propriedade intelectual com a proteção dos conhecimentos tradicionais associados. 


\section{REFERÊNCIAS}

AZEVEDO, Jane Piñeiro G. de. Os novos contornos do instituto proprietário. A função social dos direitos autorais. (In)acesso versus funcionalização. In: BORGES, Roxana Cardoso Brasileiro et al. Novas Perspectivas do Direito Privado. Belo Horizonte: Fórum, 2008.

BARBOSA, Denis Borges. Uma introdução à propriedade intelectual. 2. ed. Rio de Janeiro: Editora Lumen Juris, 2003.

BRASIL. Constituição (1988). Constituição da República Federativa do Brasil. Disponível em: $<$ http://www.planalto.gov.br/ccivil_03/constituicao/ Constituicao Compilado.htm>. Acesso em: 7 jun. 2013.

BRASIL. Ministério do Meio Ambiente. Convenção da Diversidade Biológica. 1992. Disponível em:<http://www.mma.gov.br/ biodiversidade/convencao-da-diversidade-biologica $>$. Acesso em: 7 jun. 2013.

BRASIL. Ministério do Meio Ambiente. O que é Acesso ao patrimônio genético. 2013. Disponível em: $<$ http://www.mma.gov.br/patrimoniogenetico/conselho-de-gestao-do-patrimonio-genetico/acesso-ao-patrimoniogenetico-e-aos-conhecimentos-tradicionais-associados $>$. Acesso em: 7 jun. 2013.

BRASIL. Lei n. 10.406, de 10 de janeiro de 2002. Institui o Código Civil. Disponível em:<http://www.planalto.gov.br/ccivil_03/leis/2002/L10406.htm>. Acesso em: 9 jun. 2013.

Lei n. 9.279/96 de 14 de maio de 1996. Regula direitos e obrigações relativos à Propriedade Intelectual. Disponível em: $<$ http:// www.planalto.gov.br/ ccivil_03/leis/L9279.htm>. Acesso em 08 de jun 2013.

. Medida Provisória $n^{0}$ 2.186-16 de 23.08.2001: regulamenta o inciso II do $\S 1^{\circ}$ e o $\S 4^{\circ}$ do art.225 da CD, os arts. $1^{\circ}, 8^{\circ}$, alínea “j”, 10 , alínea "c", 15 e 16, alíneas 2 e 4 da CDB, dispõe sobre o acesso ao patrimônio 
genético, a proteção ao conhecimento tradicional [...]. Disponível em: $<$ http:// www.planalto.gov.br/ccivil_03/mpv/2186-16.htm>. Acesso em: 8.jun. 2013. CANHOS, Dora Ann Lange. Patentes em biotecnologia. Campinas: Fundação Tropical de Pesquisa e Tecnologia "André Tosello", 1991.

DEL NERO, Patrícia Aurélia. Propriedade Intelectual: A tutela jurídica da biotecnologia. 2. ed. São Paulo: Revista dos Tribunais, 2004.

DERANI, Cristiane. Patrimônio genético e conhecimento tradicional associado: considerações jurídicas sobre seu acesso. In: LIMA, André (Org.). O Direito para o Brasil socioambiental. Porto Alegre: Sergio Antonio Fabris, 2002.

ENGELMANN, Wilson. A (re)leitura da teoria do fato jurídico à luz do "diálogo entre as fontes do Direito". In: CALLEGARI, André Luís et al.

Constituição, Sistemas Sociais e Hermenêutica. Porto Alegre: Livraria do Advogado, 2010. p.289-308. (Mestrado e Doutorado, v.7).

ENGELMANN, Wilson. As Nanotecnologias e a Propriedade Intelectual: desafios e possibilidades à Gestão transdisciplinar da Inovação. IN: BOFF, Salete Oro; PIMENTEL, Luiz Otavio (Org.). A Proteção Jurídica da Inovação Tecnológica. Passo Fundo: IMED, 2011. p.25-44.

FIORILLO, Celso Antônio Pacheco; DIAFÉRIA, Adriana. Biodiversidade, patrimônio genético e biotecnologia no Direito Ambiental. 2.ed. São Paulo: Saraiva, 2012.

FLORES FILHO, Edgar Gastón Jacobs. A Propriedade Intelectual e Propriedade da Cultura. In: DEL NERO, Patrícia Aurélia (Coord.)

Propriedade Intelectual e Transferência de Tecnologia. Belo Horizonte: Fórum, 2011.p.153-167.

GLASS, Verena. Acusação de biopirataria contra Natura expõe legislação falha. Repórter Brasil, 30 maio 2006. Disponível em: $<$ http:// reporterbrasil.org.br/2006/05/ acusacao-de-biopirataria-contra-natura-expoelegislacao-falha/>. Acesso em: 28 ago. 2013. 
JAYME, Erik. Direito Internacional privado e cultura pós-moderna.

Cadernos do PPGD/UFRGS 1, n.1, p.59-68, mar. 2003.

KRETZMAN, Carolina G; SPAREMBERGER, Raquel. Antropologia, multiculturalismo e Direito: o reconhecimento da identidade das comunidades tradicionais no Brasil. In: COLAÇO, Luzia. (Org.). Elementos da Antropologia Jurídica. Florianópolis: Conceito Editorial, 2008.

MARQUES, Cláudia Lima. O “diálogo das fontes” como método da nova teoria geral do direito: um tributo a Erik Jayme. In: . (Coord.).

Diálogo das Fontes: do conflito à coordenação de normas do Direito Brasileiro. São Paulo: RT, 2012. p.17-66.

MARQUES, João Paulo F. Remédio. Biotecnologia(s) e Propriedade Intelectual. Coimbra: Almedina, 2007. v.2.

ORGANIZAÇÃO DAS NAÇÕES UNIDAS (ONU). Declaração do Rio sobre Meio Ambiente e Desenvolvimento. Rio de Janeiro, 1992.

Disponível em: <http://www.onu.org.br/rio20/img/2012/01/rio92.pdf >. Acesso em: 7 jun. 2013.

SANTILLI, Juliana. Socioambientalismo e Novos Direitos. São Paulo: Peirópolis, 2005.

SHIVA, Vandana. Biopirataria: a pilhagem da natureza e do conhecimento. Petrópolis, RJ: Vozes, 2001.

THAINES, Aleteia Hummes; MELEU, Marcelino da Silva. O Papel da Propriedade Intelectual no Desenvolvimento. In: BOFF, Salete Oro; PIMENTEL, Luiz Otavio (Orgs). A Proteção Jurídica da Inovação Tecnológica. Passo Fundo: IMED, 2011. p.25-44.

UNESCO. Oral and graphic expressions of the Wajapi. 2008. Disponível em: $<$ http://www.unesco.org/culture/ich/index.php?pg=00011\&RL=00049>. Acesso em: 12 set. 2013. 
VILLA NOVA, Luciana. Biodiversidade brasileira conectando pessoas. TEDxAmazônia - um novo jeito de produzir. 2011. Disponível em: $<$ http://www.youtube.com/watch?v=oqOQZXWMf94>. Acesso em: 10 jul. 2013.

Artigo recebido em 24/06/13 e aprovado para publicação em 29/09/13

Como citar: SCHIOCCHET, Taysa; SILVA, Rodolfo Souza da. A biotecnologia e a possibilidade de compatibilização das patentes com a proteção dos conhecimentos tradicionais associados. Scientia Iuris, Londrina, v.17, n.2, p.211230, dez.2013. DOI: 10.5433/2178-8189.2013v17n2p211. 